\title{
Inbred and furious: negative association between aggression and genetic diversity in highly inbred fish
}

\author{
AMY ELLISON, $*$ + CARLOS GARCIA DE LEANIZ† and SOFIA CONSUEGRA* \\ *IBERS, Aberystwyth University, Penglais Campus, Aberystwyth SY23 3DA, UK, †Department of Biosciences, Swansea \\ University, Swansea SA2 8PP, UK
}

\begin{abstract}
Aggressive behaviour plays an important role in securing resources, defending against predators and shaping social interactions. Although aggression can have positive effects on growth and reproductive success, it is also energetically costly and may increase injury and compromise survival. Individual genetic diversity has been positively associated with aggression, but the cause for such an association is not clear, and it might be related to the ability to recognize kin. To disentangle the relationships between genetic diversity, kinship and aggression, we quantified aggressive behaviour in a wild, self-fertilizing fish (Kryptolebias marmoratus) with naturally variable degrees of genetic diversity, relatedness and familiarity. We found that in contrast to captive fish, levels of aggression among wild K. marmoratus are positively associated with individual homozygosity, but not with relatedness or familiarity. We suggest that the higher aggression shown by homozygous fish could be related to better kin discrimination and may be facilitated by hermaphrodite competition for scarce males, given the fitness advantages provided by outcrossing in terms of parasite resistance. It seems likely that the relationship between aggression and genetic diversity is largely influenced by both the environment and population history.
\end{abstract}

Keywords: aggression, heterozygosity, inbreeding, Kryptolebias marmoratus, relatedness, selffertilization

Received 26 September 2012; revision received 17 December 2012; accepted 20 December 2012

\section{Introduction}

Aggressive behaviour plays an important role in securing food (Bryant \& Grant 1995) and mates (CluttonBrock et al. 2006), in defending against predators (Huntingford 1976) and in establishing social hierarchies (Oswald \& Erwin 1976; Dloniak et al. 2006). Aggression can have a positive effect on growth (Höjesjö et al. 2002), reproductive success (Horn 1974; Meagher et al. 2000) and survival (Smith \& Blumstein 2008) but is also costly in terms of energy expenditure (Jakobsson et al. 1995; Marler et al. 1995), injury risk (Grant 1997) or predation (Jakobsson et al. 1995).

Correspondence: Sofia Consuegra, Fax: +44(0)1970 622350;

E-mail: skc@aber.ac.uk

${ }^{\ddagger}$ Current address: Department of Ecology and Evolutionary Biology, Cornell University, Corson Hall, Ithaca, NY, 14853, USA
Therefore, individuals may be expected to modulate aggressive behaviour depending on the relative costs/ risks and benefits (Réale et al. 2007). Individual variation in behaviour, including aggression, is maintained, at least partially, by the existence of behavioural syndromes (suites of correlated behaviours across contexts; Sih et al. 2004). For example, more aggressive individuals are also more likely to take risks (Brick \& Jakobsson 2002; Reaney \& Backwell 2007). But aggression also has an important genetic component (Vrontou et al. 2006; Edwards et al. 2009) that has evolutionary implications across taxa, from insects to humans (Zwarts et al. 2011).

According to kin selection theory, individuals should exhibit reduced aggression towards kin compared to unrelated conspecifics, as they will gain indirect fitness benefits by decreasing their relatives' costs of fighting and/or by contributing to their access to limited resources (Hamilton 1964). This may explain why animals living in groups often display reduced aggression 
against their close relatives, a phenomenon seen across multiple taxa, from invertebrates (Pirk et al. 2001; Giron et al. 2004), fish (Hert 1985; Olsén \& Järvi 1997) to birds (Pravosudova et al. 2001; Reynolds et al. 2009) and mammals (Blumstein et al. 2002; Widdig et al. 2006). Yet, exceptions to this rule also abound, and a lack of association between aggression and relatedness has also been documented, both in solitary (Lode 2008) and in social species (Tóth et al. 2009).

Genetic diversity has been found to be positively associated with aggression in colonial ants (Tsutsui et al. 2000), primates (Charpentier et al. 2008), rodents (Boonstra et al. 1994; Eklund 1996) and fish (Tiira et al. 2003, 2006); it also seems to be related with risk-taking behaviour (Vilhunen et al. 2008). However, the underlying mechanisms of this relationship are unclear, and it could possibly be related to the ability of individuals to recognize kin, as kin discrimination plays an important role in inbreeding avoidance and maintenance of genetic diversity (Pusey \& Wolf 1996; Penn \& Potts 1999; Komdeur et al. 2004). In some species, kin recognition appears to be innate (Mateo \& Johnston 2000; Bull et al. 2001), whereas in other species, a period of learning is required to recognize siblings (Olsén et al. 2002). However, individuals can also learn to recognize conspecifics they have previously encountered or interacted with (familiar), despite being unrelated (Komdeur et al. 2004). In fact, reduced aggression has been observed between familiar individuals (Utne-Palm \& Hart 2000), often irrespective of their relatedness (Stookey \& Gonyou 1998; Lode 2008).

Extreme inbreeding seems to impair the ability of individuals to discriminate between individuals when they are genetically similar or identical (Nevison et al. 2000, 2003). This may explain why inbred animals display lower aggression among related individuals, while maintaining high aggression levels towards those genetically distinct (Nevison et al. 2003; Tsutsui et al. 2003). However, a relationship between heterozygosity, aggression and dominance has been observed in captive-bred populations even in the absence of inbreeding (Tiira et al. 2003, 2006), and it has been suggested that the role of genetic diversity in dominance and aggression can depend on the genetic background and population history (Tiira et al. 2006). For example, juvenile salmonids show marked differences in behaviour between natural and captive conditions and seem less prone to associate with kin in the wild, where heterogeneous advantage can overweigh the advantages of kin association (Griffiths \& Armstrong 2001). Finding a clear relationship among genetic diversity, inbreeding and aggression is probably hampered by the fact that aggression is a quantitative trait with complex genetic architecture and strong epistatic and pleiotropic effects (Zwarts et al. 2011).
Kryptolebias marmoratus (the mangrove rivulus) is an ideal species to test the effects of inbreeding and genetic diversity on aggression, as natural populations are composed of highly inbred, self-fertilizing hermaphrodite fish that coexist with a small proportion of males capable of outcrossing with hermaphrodites, thereby increasing genetic diversity (Mackiewicz et al. 2006a). Highly homozygous hermaphrodites reared in the laboratory tend to exhibit less aggression towards fish of the same selfing strain and prefer to associate with familiar individuals, irrespective of their relatedness (Edenbrow \& Croft 2012a). However, in the wild, outbred offspring have higher genetic diversity and lower parasite loads than selfed inbred fish (Ellison et al. 2011), suggesting that genetic diversity may confer a fitness advantage and influence aggression levels in ways that may not be detected in laboratory strains. To disentangle the relationships between genetic diversity, kinship and aggression, we analysed the aggression levels of wild K. marmoratus having naturally variable degrees of genetic diversity, relatedness and familiarity. Given the inbred nature of the species, our expectation was that aggression levels would increase with decreasing relatedness and familiarity.

\section{Materials and methods}

\section{Experimental animals}

Sixty wild Kryptolebias marmoratus were collected on December 2009 from the burrows of land crabs (Cardisoma guanhumi) by using cup traps (Mackiewicz et al. 2006a) at four sampling locations in Calabash Caye, Turneffe Atoll, Belize $\left(17^{\circ} 16^{\prime} \mathrm{N}, 87^{\circ} 48^{\prime} \mathrm{W}\right)$ (Ellison et al. 2011, 2012). Prior to trials, all fish were individually held for $24-48 \mathrm{~h}$ in 200-mL containers and fed newly hatched brine shrimp (Artemia salina) nauplii daily.

\section{Behavioural trials}

Twenty-five behavioural trials were carried out at Calabash Field Station using pairs of fish (dyads) ranging in standard length between 15 and $32 \mathrm{~mm}$. Ten control trials were also run with a single fish to ensure that behaviours observed were directed towards the 'opponent' fish and did not simply represent a response to a novel environment. In every trial, the behaviour of each fish was recorded simultaneously by two observers working independently. A subset of five trials was filmed and checked to ensure consensus between observers. Behavioural trials were carried out in an experimental aquarium of $20 \times 10 \times 15 \mathrm{~cm}$ (Fig. 1) without substrate, filled with $1.6 \mathrm{~L}$ of natural brackish water and divided into two equal sections by a perforated transparent partition. The partition allowed fish to detect their 'opponent' 


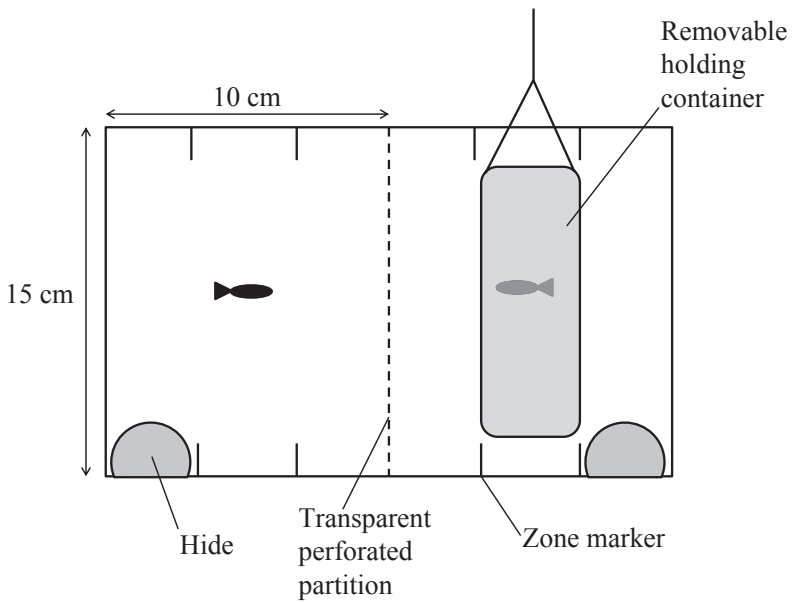

Fig. 1 Schematic representation of the experimental tank used for analysing the behaviour of wild Kryptolebias marmoratus.

both visually and via olfaction. To prevent carry over effects, the tank was drained, cleaned with $70 \%$ ethanol, and the water changed between trials. Each side of the experimental tank was marked into three equal zones, and hides were positioned in the zones located furthest from the partition. For each trial, two fish were placed in either side of the aquarium in opaque holding containers and allowed to acclimatize for $5 \mathrm{~min}$. The fish were then released and observed for a total of $10 \mathrm{~min}$, and their positions in the tank recorded every $30 \mathrm{~s}$. The numbers of attacks (head-butting or biting at the partition) or retreats (rapid movement away from the partition) were recorded (Martin 2007; Molloy et al. 2011). Fish dyads were classified according to their origin and three decreasing levels of expected familiarity (i.e. collected from the same crab burrow, collected at the same sampling site but from different burrows or collected at different sampling sites). Thus, sampling origin was used as a proxy for expected familiarity: fish captured in the same burrow (seven pairs) were expected to be more familiar than those fish from the same site but from different burrows (nine pairs), while fish from different sites (nine pairs) were expected to be the most unfamiliar (Ward et al. 2007). Pairs of fish were size matched within $\pm 1 \mathrm{~mm}$ standard lengths to control for the effects of size dominance (Molloy et al. 2011) and randomly assigned to either side of the experimental tank to avoid position bias. Fish were used in only one trial. After the experiments, fish were euthanized with an overdose of anaesthetic (according to Home Office Schedule One methods).

\section{Genetic analyses}

Total genomic DNA was extracted from muscle tissue using the Wizard ${ }^{\circledR}$ SV 96 DNA Purification Kit (Promega Corp.). DNA was quantified using the
NANODROP1000 v.3.7 Spectrophotometer (C2008 Thermo Fisher Scientific). Thirty-two microsatellite loci (Mackiewicz et al. 2006b) were amplified in four different multiplex combinations as described in Ellison et al. (2011). Pairwise relatedness values (Lynch \& Ritland 1999) were calculated using Genalex v.6 (Peakall \& Smouse 2006). We estimated observed heterozygosity and standardized heterozygosity (Coltman et al., 1999) as well as homozygosity by loci (HL), a measure that weighs the contribution of each locus to overall heterozygosity depending on its allelic variability (Aparicio et al. 2006). All measures of heterozygosity were highly correlated (Obs. and Std. Het; $r=1, P<0.001$, Obs. Het and HL; $r=-0.997$, $P<0.001$, Std. Het and HL; $r=-0.997, P<0.001)$; therefore, only HL was used for subsequent analyses. To test whether our panel of markers was likely to reflect genomewide homozygosity, we employed David's g2 implemented in RMES that measures identity disequilibrium among loci (David et al. 2007).

\section{Data analysis}

Heterozygosity (HL) was arcsine transformed, and the number of attacks and retreats was square-root-transformed to attain normality and homogeneity of variances. The level of aggression (i.e. number of attacks, retreats and average distance from opponent) was compared between control trials (no opponent) and trials with stimulus fish (with opponent) using t-tests. The relationship between length and heterozygosity was analysed by Pearson correlation, as in male K. marmoratus size and aggression can be associated (Molloy et al. 2011).

For trials with an opponent, to summarize the variation in aggression behaviours measured (i.e. attacks, retreats and distance from opponent), principal component analysis (PCA) was performed. We employed linear mixed modelling using the NLME PACKAGE v. 3.1-105 (Pinheiro et al. 2012) within R 2.15.1 to analyse aggression data (square-root-transformed) in relation to relatedness, familiarity, body length and heterozygosity, with fish ID as a random factor nested within pairs. Continuous variables in the model were normally distributed (Kolmogorov one sample test, heterozygosity $P=0.245$; square root (aggression), $P=0.153$, relatedness $P=0.690$, body length $P=0.394$ ) and the error variances homogeneous with respect to familiarity score (Levene's test $P=0.642$ ). The full model included heterozygosity, body length, familiarity and relatedness as factors plus all two-term interactions, and the minimal adequate model was fitted by maximum likelihood (BIC).

To assess whether the relationship between genetic diversity and aggression was the result of whole-genome or locus-specific heterozygosities, we repeated the linear 

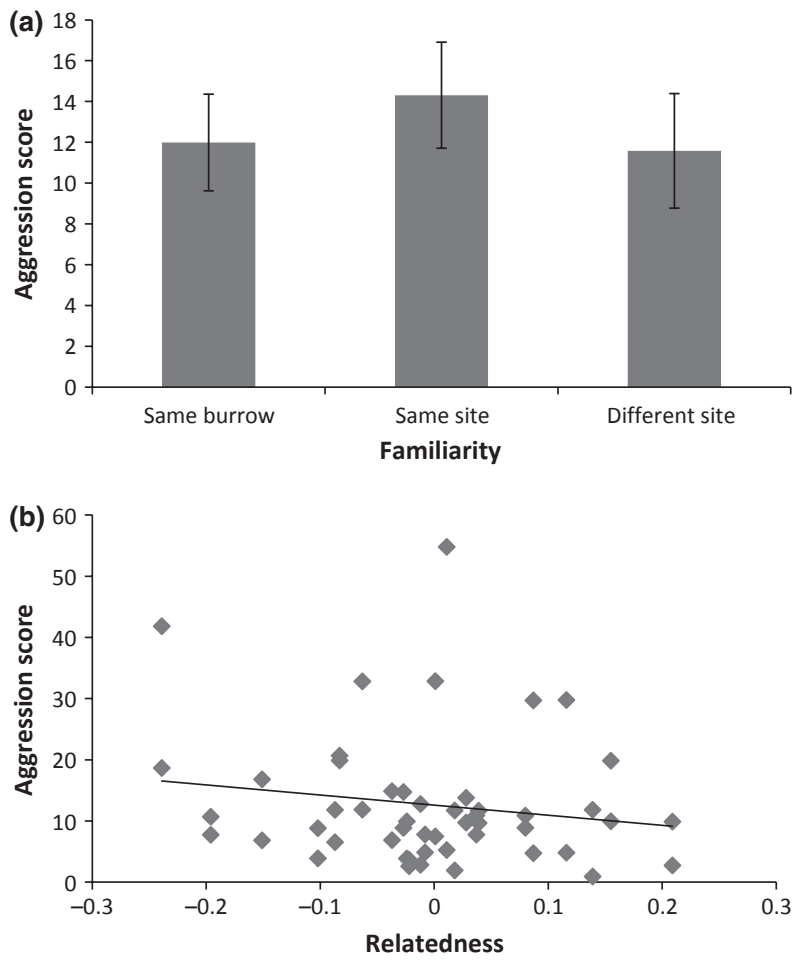

Fig. 2 Relationship between aggression scores and (a) familiarity (using sampling site as a proxy) and (b) relatedness in wild Kryptolebias marmoratus. Aggression score is based on the principal component analysis of number of attacks, retreats and average distance from opponent during behavioural trials.

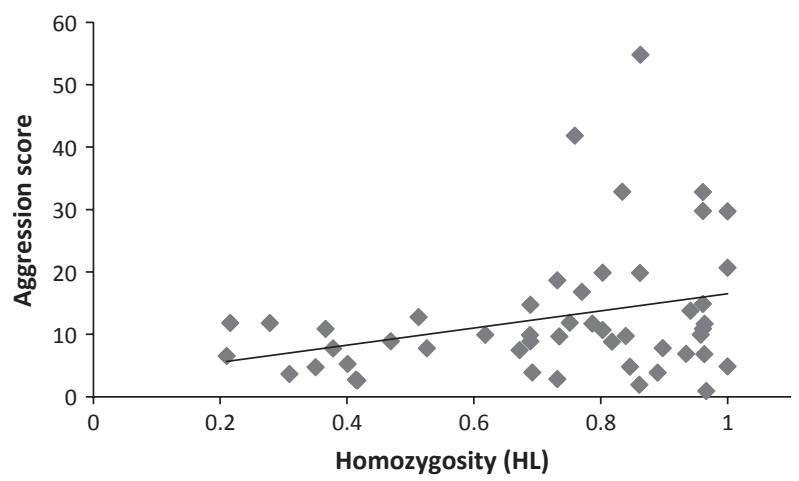

Fig. 3 Relationship between individual genetic diversity (homozygosity by locus, HL) and aggression score in wild Kryptolebias marmoratus. Aggression score is based on the principal component analysis of number of attacks, retreats and average distance from opponent during behavioural trials.

mixed modelling at each of the 32 individual loci, with fish ID as a random factor nested within pairs.

\section{Results}

Consensus between observers was $100 \%$ for number of retreats and distance from opponent while consensus for number of attacks was $98.4 \%$. Fish with identical genotypes were not observed. Individual heterozygosity values ranged between 0.210 and 1.000 and relatedness values between pairs varied between -0.239 and 0.209 . Identity disequilibrium measured by $g 2$ was significantly higher than zero $(g 2=0.497, \quad S E=0.105$, $P=0.000$, based on 1000 iterations), indicating that the set molecular markers used here is informative of underlying inbreeding. No significant correlation was found between heterozygosity and fish length (Pearson's correlation test $r=-0.135, P=0.194$ ).

In control trials with no opponent fish present, fish displayed significantly fewer attacks and retreats from the partition than in trials with an opponent present (attacks: control $=0.50 \pm 0.71$, opponent $=14.30 \pm 11.90$, $t=-11.16, \quad P<0.001 ; \quad$ retreats: $\quad$ control $=0.20 \pm 0.42$, opponent $=3.15 \pm 3.28, t=-8.92, P<0.001)$. Control fish also were on average further away from the tank partition than opponents (control $=4.82 \pm 0.89$, opponent $=3.82 \pm 1.09, t=3.10, P=0.007)$.

The first component of the PCA of all aggression measures explained $89.3 \%$ of the variation among individuals. The highest loading on this first component was number of attacks (0.999), higher number of attacks resulting in higher scores. The minimal adequate model fitted by maximum likelihood included only heterozygosity as a significant predictor $\left(t_{24}=2.17, P=0.04\right.$ Figs 2 and 3) and indicated that the more homozygous the fish were, the more aggressive were likely to be (Table 1). Analysis of variance components indicated that $99.9 \%$ of the variance was due to differences among fish within pairs, and $<0.01 \%$ was due to variation among pairs. None of the individual comparisons were significant after Bonferroni correction (Supporting information Table S1), indicating that it was global heterozygosity, and not individual loci, what was having an effect on aggression.

\section{Discussion}

Contrary to our expectations, we found no significant association between relatedness and aggression in wild hermaphrodite K. marmoratus. This is in contrast to previous observations in captive-bred fish, where hermaphrodites K. marmoratus displayed reduced aggression towards kin (Edenbrow \& Croft 2012a). These contrasting results may reflect behavioural differences between wild fish and those bred over several generations in captivity. Captivity can relax natural selective pressures, altering time/energy budgets and consequently behaviour (Huntingford 2004). For example, captive animals do not need to devote large proportions of time to foraging and can therefore increase energetically costly behaviours such as aggression. In addition, the lack of natural enemies (e. g. predators) can make captive individuals more 
Table 1 Results of linear mixed modelling aimed at evaluating the effects of heterozygosity, relatedness, body length and familiarity on aggression (summarized by principal component analysis scores) of individual fish nested within dyads

\begin{tabular}{lcc}
\hline & $t$-value & $P$-value \\
\hline Full model (BIC = 209.83) & & \\
Heterozygosity (HL) & -0.179 & 0.859 \\
Relatedness (R) & 0.374 & 0.712 \\
Length (L) & 0.014 & 0.989 \\
Familiarity (F) & -1.099 & 0.284 \\
HL $\times$ R & 0.271 & 0.789 \\
HL $\times$ L & -0.098 & 0.923 \\
HL $\times$ F & 1.493 & 0.153 \\
R $\times$ L & -0.725 & 0.478 \\
R $\times$ F & -0.558 & 0.583 \\
L $\times$ F & 0.524 & 0.607 \\
Minimal adequate model (BIC $=183.502)$ & \\
Heterozygosity (HL) & 2.171 & 0.040 \\
\hline
\end{tabular}

BIC values for the full and minimal adequate models are detailed. Significant values are given in bold.

risk-taking (Roberts et al. 2011), and increased aggression is commonly observed in many captive-bred fish species (McPhee 2004; Kelley et al. 2006; Salonen \& Peuhkuri 2006; Blanchet et al. 2008). We tested our fish within $48 \mathrm{~h}$ of capture in all cases and in the same environmental conditions where they naturally live; we are therefore confident that behaviours observed in situ in our study are likely to reflect natural behaviours present in the wild. However, differences in heterozygosity as well as in the proportion of males have been observed among K. marmoratus populations from different geographical origins (e.g. Florida and Belize; Mackiewicz et al. 2006a) that could affect kin recognition. We cannot therefore rule out that individual differences in stress response after capture might have affected aggression levels (Øverli et al. 2004). Thus, further tests comparing wildand captive-bred fish from the same origin kept under the same conditions should shed light into the relative roles of captive rearing and geographical origin in modulating aggression on this species.

In our study, sampling location was used as a proxy for familiarity between fish dyads. Fish captured in the same crab burrow were assumed to be the most familiar, as they would have had previous direct contact with one another. Fish from the same location were assumed to have an intermediate level of familiarity, would have experienced similar habitat conditions (Ellison et al. 2012) and would likely have had previous encounters. Familiarity by local habitat has previously been demonstrated in other fish species (Ward et al. 2007). Fish from separate sampling locations (more than $560 \mathrm{~m}$ apart) were assumed to be unfamiliar, as they were less likely to have encountered one another. Familiarity can help stabilize and maintain dominance hierarchies, thereby reducing costly aggressive behaviours and energetic expenditure contesting for resources (Hojesjo et al. 1998). Although primarily solitary (Mackiewicz et al. 2006c), multiple K. marmoratus are commonly found in crab burrow refuges (Taylor 1990) and other habitats (Taylor et al. 2008). Thus, modulation of aggression towards familiar conspecifics may be beneficial during such aggregations on this species. However, here familiarity was not a significant predictor of aggression in wild fish. This could be explained because, in contrast with captive K. marmoratus (Edenbrow \& Croft 2012a), our individuals displayed a wide range of genetic diversity and different degrees of relatedness, representative of the real diversity found in the natural environment, potentially giving the fish a wider range of opportunities for different individual interactions. On the other hand, familiarity can take some time to develop (Griffiths \& Magurran 1997), and as we do not know for how long our fish had been together at the sampling burrows, it is also possible that they had not been together for long enough to develop familiarity.

Probably, the most surprising result of our study is the significant negative association between aggression and heterozygosity. Associations of fitness-related traits (such as aggression) with multilocus heterozygosity based upon neutral microsatellite loci can result from genomewide distributed fitness loci (general effects) or by one or more microsatellite loci closely linked with specific fitness loci (local effects) (Hansson \& Westerberg 2002). Our results suggested a general effect of homozygosity. Although the negative relationship between heterozygosity and aggression was contrary to our expectations based on previous observations on other species (Eklund 1996; Tiira et al. 2003, 2006; Charpentier et al. 2008), homozygosity may increase aggression in species that are naturally highly homozygous. This is likely because the most homozygous individuals should discriminate more easily between similar and dissimilar genotypes (Zeh \& Zeh 1997; but see Rosset et al. 2007). For example, the ability of inbred mice to discriminate between individuals seems to be low towards genetically similar individuals but high when they are highly divergent (Nevison et al. 2003). The Argentine invasive ant also shows an inverse association between aggression and individual microsatellite diversity, and it has been suggested that this may facilitate kin discrimination when genetic variation involved in kin recognition decreases, for example following bottlenecks (Tsutsui et al. 2003). Such a mechanism might explain both the higher aggression against highly divergent selfing laboratory lines (Edenbrow \& Croft 2012a), and the increasing aggression shown by homozygous individuals found in our study. 


\section{A. ELLISON, C. GARCIA DE LEANIZ and S. CONSUEGRA}

High levels of intrasexual aggression have been observed in both hermaphrodite (Martin 2007; Luke \& Bechler 2010) and male (Martin 2007; Molloy et al. 2011) Kryptolebias marmoratus. In contrast, hermaphrodite-male aggression appears to be less frequent (Martin 2007). Although male aggressiveness in K. marmoratus seems to be uncorrelated with individual genetic diversity (Molloy et al. 2011), heterozygosity appears to influence male size with larger males having greater success in intrasexual contests than smaller ones (Molloy et al. 2011). Levels of aggression in highly homozygous laboratory K. marmoratus display a strong genetic component but do not appear to differ between males and hermaphrodites (Edenbrow \& Croft 2012b). However, compared to captive fish, natural populations display more marked differences in male and hermaphrodite frequencies, as well as higher genetic diversity that, together with stronger selective pressures, might be expected to affect agonistic interactions. Heterozygous fish tend to have lower parasite loads and thus have a potential fitness advantage (Ellison et al. 2011), suggesting that outcrossing with males could be beneficial and increase competition for mates and aggression rates among hermaphrodites. Fish parasites can modify social interactions (Croft et al. 2011) and increase risk-taking behaviour and aggression in their hosts (Arnott et al. 1990; Barber et al. 1995; Levri 1999; Ward et al. 2002, 2005; Mikheev et al. 2010) by increasing metabolic demands (Ward et al. 2005) or by direct host manipulation (Levri 1999; Mikheev et al. 2010). Given that more homozygous K. marmoratus also have higher parasite loads, it is possible that parasites could manipulate the fish host and make it more aggressive, an intriguing possibility that deserves investigation.

In summary, we found that, in contrast to captivereared fish, levels of aggression in wild $K$. marmoratus are associated with individual homozygosity, but not with relatedness or familiarity. The higher levels of genetic diversity and relatedness displayed by wild fish could explain the lack of association between aggression relatedness and familiarity observed in natural conditions. Given the fitness advantages provided by outcrossing in terms of parasite resistance, the high levels of aggression shown by homozygous fish could also reflect better discrimination ability, perhaps facilitated by hermaphrodite competition for scarce males, although this hypothesis warrants further study. What seems clear, however, is that the relationship between aggression and genetic diversity is probably dependent on both the environment and population history.

\section{Acknowledgements}

We want to thank S. Taylor, P. Wright, S. Currie, C. Cooper and K. Regan for help in collecting the samples. Funding was provided by a Waitt grant from the National Geographic
Society (W76-09) to SC and an IBERS PhD scholarship to AE.

\section{References}

Aparicio JM, Ortego J, Cordero PJ (2006) What should we weigh to estimate heterozygosity, alleles or loci? Molecular Ecology, 15, 4659-4665.

Arnott MA, Cassella JP, Aitken PP, Hay J (1990) Social interactions of mice with congenital Toxoplasma infection. Annals of Tropical Medicine and Parasitology, 84, 149-156.

Barber I, Huntingford FA, Crompton DWT (1995) The effect of hunger and cestode parasitism on the shoaling decisions of small freshwater fish. Journal of Fish Biology, 47, 524-536.

Blanchet S, Paez DJ, Bernatchez L, Dodson JJ (2008) An integrated comparison of captive-bred and wild Atlantic salmon (Salmo salar): implications for supportive breeding programs. Biological Conservation, 141, 1989-1999.

Blumstein DT, Ardron JG, Evans CS (2002) Kin discrimination in a macropod marsupial. Ethology, 108, 815-823.

Boonstra R, Hochachka WM, Pavone L (1994) Heterozygosity, aggression, and population fluctuations in meadow voles (Microtus pennsylvanicus). Evolution, 48, 1350-1363.

Brick O, Jakobsson S (2002) Individual variation in risk taking: the effect of a predatory threat on fighting behavior in Nannacara anomala. Behavioral Ecology, 13, 439-442.

Bryant MJ, Grant JWA (1995) Resource defence, monopolization and variation of fitness in groups of female Japanese medaka depend on the synchrony of food arrival. Animal Behaviour, 49, 1469-1479.

Bull M, Griffin C, Bonnett M, Gardner M, Cooper S (2001) Discrimination between related and unrelated individuals in the Australian lizard Egernia striolata. Behavioral Ecology and Sociobiology, 50, 173-179.

Charpentier M, Prugnolle F, Gimenez O, Widdig A (2008) Genetic heterozygosity and sociality in a primate species. Behavior Genetics, 38, 151-158.

Clutton-Brock TH, Hodge SJ, Spong G et al. (2006) Intrasexual competition and sexual selection in cooperative mammals. Nature, 444, 1065-1068.

Coltman DW, Pilkington JG, Smith JA, Pemberton JM (1999) Parasite-mediated selection against inbred Soay sheep in a free-living, island population. Evolution, 53, 1259-1267.

Croft D, Edenbrow M, Darden S, Ramnarine IW, van Oosterhout C, Cable J et al. (2011) Effect of gyrodactylid ectoparasites on host behaviour and social network structure in guppies Poecilia reticulata. Behavioral Ecology and Sociobiology, 65, 2219-2227.

David P, Pujol B, Viard F, Castella V, Goudet J (2007) Reliable selfing rate estimates from imperfect population genetic data. Molecular Ecology, 16, 2474-2487.

Dloniak SM, French JA, Holekamp KE (2006) Rank-related maternal effects of androgens on behaviour in wild spotted hyaenas. Nature, 440, 1190-1193.

Edenbrow M, Croft DP (2012a) Kin and familiarity influence association preferences and aggression in the mangrove killifish Kryptolebias marmoratus. Journal of Fish Biology, 80, 503-518.

Edenbrow M, Croft DP (2012b) Sequential hermaphroditism and personality in a clonal vertebrate: the mangrove killifish. Behavioural Processes, 90, 229-237. 
Edwards A, Zwarts L, Yamamoto A, Callaerts P, Mackay T (2009) Mutations in many genes affect aggressive behavior in Drosophila melanogaster. BMC Biology, 7, 29.

Eklund A (1996) The effects of inbreeding on aggression in wild male house mice (Mus domesticus). Behaviour, 133, 883-901.

Ellison A, Cable J, Consuegra S (2011) Best of both worlds? Association between outcrossing and parasite loads in a selfing fish. Evolution, 65, 3021-3026.

Ellison A, Wright P, Taylor DS et al. (2012) Environmental diel variation, parasite loads, and local population structuring of a mixed-mating mangrove fish. Ecology and Evolution, 2, $1682-1695$.

Giron D, Dunn DW, Hardy ICW, Strand MR (2004) Aggression by polyembryonic wasp soldiers correlates with kinship but not resource competition. Nature, 430, 676-679.

Grant JA (1997) Territoriality. In: Behavioural Ecology of Teleost Fishes (ed. Godin J. G. J.), pp. 81-103. Oxford University Press, Oxford.

Griffiths SW, Armstrong JD (2001) The benefits of genetic diversity outweigh those of kin association in a territorial animal. Proceedings of the Royal Society of London. Series B: Biological Sciences, 268, 1293-1296.

Griffiths SW, Magurran AE (1997) Familiarity in schooling fish: how long does it take to acquire? Animal Behaviour, 53, 945-949.

Hamilton WD (1964) The genetical evolution of social behaviour. I. Journal of Theoretical Biology, 7, 1-16.

Hansson B, Westerberg L (2002) On the correlation between heterozygosity and fitness in natural populations. Molecular Ecology, 11, 2467-2474.

Hert E (1985) Individual recognition of helpers by the breeders in the cichlid fish Lamprologus brichardi (Poll, 1974). Zeitschrift für Tierpsychologie, 68, 313-325.

Hojesjo J, Johnsson JI, Petersson E, Jarvi T (1998) The importance of being familiar: individual recognition and social behavior in sea trout (Salmo trutta). Behavioral Ecology, 9, 445-451.

Höjesjö J, Johnsson JI, Bohlin T (2002) Can laboratory studies on dominance predict fitness of young brown trout in the wild? Behavioral Ecology and Sociobiology, 52, 102-108.

Horn J (1974) Aggression as a component of relative fitness in four inbred strains of mice. Behavior Genetics, 4, 373-381.

Huntingford FA (1976) The relationship between anti-predator behaviour and aggression among conspecifics in the threespined stickleback, Gasterosteus aculeatus. Animal Behaviour, 24, 245-260.

Huntingford FA (2004) Implications of domestication and rearing conditions for the behaviour of cultivated fishes. Journal of Fish Biology, 65, 122-142.

Jakobsson S, Brick O, Kullberg C (1995) Escalated fighting behaviour incurs increased predation risk. Animal Behaviour, 49, 235-239.

Kelley JL, Magurran AE, Macias Garcia C (2006) Captive breeding promotes aggression in an endangered Mexican fish. Biological Conservation, 133, 169-177.

Komdeur J, Richardson DS, Burke T (2004) Experimental evidence that kin discrimination in the Seychelles warbler is based on association and not on genetic relatedness. Proceedings of the Royal Society of London. Series B: Biological Sciences, 271, 963-969.

Levri EP (1999) Parasite-induced change in host behavior of a freshwater snail: parasitic manipulation or byproduct of infection? Behavioral Ecology, 10, 234-241.
Lode T (2008) Kin recognition versus familiarity in a solitary mustelid, the European polecat Mustela putorius. Comptes Rendus Biologies, 331, 248-254.

Luke KN, Bechler DL (2010) The role of dyadic interactions in the mixed-mating strategies of the mangrove rivulus Kryptolebias marmoratus. Current Zoology, 56, 6-17.

Lynch M, Ritland K (1999) Estimation of pairwise relatedness with molecular markers. Genetics, 152, 1753-1766.

Mackiewicz M, Tatarenkov A, Taylor DS, Turner BJ, Avise JC (2006a) Extensive outcrossing and androdioecy in a vertebrate species that otherwise reproduces as a self-fertilizing hermaphrodite. Proceedings of the National Academy of Sciences, 103, 9924-9928.

Mackiewicz M, Tatarenkov A, Perry A et al. (2006b) Microsatellite documentation of male-mediated outcrossing between inbred laboratory strains of the self-fertilizing mangrove killifish (Kryptolebias marmoratus). Journal of Heredity, 97, 508513.

Mackiewicz M, Tatarenkov A, Turner BJ, Avise JC (2006c) A mixed-mating strategy in a hermaphroditic vertebrate. Proceedings of the Royal Society B: Biological Sciences, 273, 2449-2452.

Marler CA, Walsberg G, White ML, Moore M, Marler CA (1995) Increased energy expenditure due to increased territorial defense in male lizards after phenotypic manipulation. Behavioral Ecology and Sociobiology, 37, 225-231.

Martin SB (2007) Association behaviour of the self-fertilizing Kryptolebias marmoratus (Poey): the influence of microhabitat use on the potential for a complex mating system. Journal of Fish Biology, 71, 1383-1392.

Mateo JM, Johnston RE (2000) Kin recognition and the "armpit effect": evidence of self-referent phenotype matching. Proceedings of the Royal Society B: Biological Sciences, 267, 695-700.

McPhee EM (2004) Generations in captivity increases behavioral variance: considerations for captive breeding and reintroduction programs. Biological Conservation, 115, 71-77.

Meagher S, Penn DJ, Potts WK (2000) Male-male competition magnifies inbreeding depression in wild house mice. Proceedings of the National Academy of Sciences, 97, 3324-3329.

Mikheev VN, Pasternak AF, Taskinen J, Valtonen ET (2010) Parasite-induced aggression and impaired contest ability in a fish host. Parasites and Vectors, 3, 17.

Molloy PP, Nyboer EA, Côté IM (2011) Male-male competition in a mixed-mating fish. Ethology, 117, 586-596.

Nevison CM, Barnard CJ, Beynon RJ, Hurst JL (2000) The consequences of inbreeding for recognizing competitors. Proceedings of the Royal Society B: Biological Sciences, 267, 687-694.

Nevison CM, Barnard CJ, Hurst JL (2003) The consequence of inbreeding for modulating social relationships between competitors. Applied Animal Behaviour Science, 81, 387-398.

Olsén KH, Järvi T (1997) Effects of kinship on aggression and RNA content in juvenile Arctic charr. Journal of Fish Biology, 51, 422-435.

Olsén KH, Grahn M, Lohm J (2002) Influence of MHC on sibling discrimination in Arctic char, Salvelinus alpinus (L.). Journal of Chemical Ecology, 28, 783-795.

Oswald M, Erwin J (1976) Control of intragroup aggression by male pigtail monkeys (Macaca nemestrina). Nature, 262, 686688.

Øverli Ø, Korzan WJ, Höglund E et al. (2004) Stress coping style predicts aggression and social dominance in rainbow trout. Hormones and Behavior, 45, 235-241. 


\section{A. ELLISON, C. GARCIA DE LEANIZ and S. CONSUEGRA}

Parasite-mediated selection against inbred Soay sheep in a free-living, island population. (1999) Coltman DW, Pilkington JG, Smith JA and Pemberton JM. Evolution, 53, 12591267.

Peakall ROD, Smouse PE (2006) genalex 6: genetic analysis in Excel. Population genetic software for teaching and research. Molecular Ecology Notes, 6, 288-295.

Penn DJ, Potts WK (1999) The Evolution of Mating Preferences and Major Histocompatibility Complex Genes, pp. 145-164. The University of Chicago Press for The American Society of Naturalists, 153.

Pinheiro J, Bates D, DebRoy S, Sarkar D (2012) nlme Version: 3.1-105. Linear and Nonlinear Mixed Effects Models. The R Core team, 24 Sep 2012, R Core Team, The Comprehensive R Archive Network cran.r-project.org/.

Pirk CWW, Neumann P, Moritz RFA, Pamilo P (2001) Intranest relatedness and nestmate recognition in the meadow ant Formica pratensis (R.). Behavioral Ecology and Sociobiology, 49, 366374

Pravosudova EV, Grubb TC, Parker PG (2001) The influence of kinship on nutritional condition and aggression levels in winter social groups of tufted titmice. The Condor, 103, 821828.

Pusey A, Wolf M (1996) Inbreeding avoidance in animals. Trends in Ecology and Evolution, 11, 201-206.

Réale D, Reader SM, Sol D, McDougall PT, Dingemanse NJ (2007) Integrating animal temperament within ecology and evolution. Biological Reviews, 82, 291-318.

Reaney LT, Backwell PRY (2007) Risk-taking behavior predicts aggression and mating success in a fiddler crab. Behavioral Ecology, 18, 521-525.

Reynolds SM, Christman MC, Uy JAC, Patricellie GL, Brauna MJ and Borgia G et al. (2009) Lekking satin bowerbird males aggregate with relatives to mitigate aggression. Behavioral Ecology, 20, 410-415.

Roberts LJ, Taylor J, Garcia de Leaniz C (2011) Environmental enrichment reduces maladaptive risk-taking behavior in salmon reared for conservation. Biological Conservation, 144, 1972-1979.

Rosset H, Schwander T, Chapuisat M (2007) Nestmate recognition and levels of aggression are not altered by changes in genetic diversity in a socially polymorphic ant. Animal Behaviour, 74, 951-956.

Salonen A, Peuhkuri N (2006) The effect of captive breeding on aggressive behaviour of European grayling, Thymallus thymallus, in different contexts. Animal Behaviour, 72, 819-825.

Sih A, Bell A, Johnson JC (2004) Behavioral syndromes: an ecological and evolutionary overview. Trends in Ecology and Evolution, 19, 372-378.

Smith BR, Blumstein DT (2008) Fitness consequences of personality: a meta-analysis. Behavioral Ecology, 19, 448-455.

Stookey JM, Gonyou HW (1998) Recognition in swine: recognition through familiarity or genetic relatedness? Applied Animal Behaviour Science, 55, 291-305.

Taylor DS (1990) Adaptive specializations of the Cyprinodont fish Rivulus marmoratus. Florida Scientist, 53, 238-248.

Taylor DS, Turner BJ, Davis WP, Chapman BB (2008) A novel terrestrial fish habitat inside emergent logs. The American Naturalist, 171, 263-266.

Tiira K, Laurila A, Peuhkuri N, Piironen J, Ranta E, Primmer CR et al. (2003) Aggressiveness is associated with genetic diversity in landlocked salmon (Salmo salar). Molecular Ecology, 12, 2399-2407.

Tiira K, Laurila A, Enberg K et al. (2006) Do dominants have higher heterozygosity? Social status and genetic variation in brown trout, Salmo trutta. Behavioral Ecology and Sociobiology, 59, 657-665.

Tóth Z, Bókony V, Lendvai Á, Szabó K, Pénzes K, Liker A et al. (2009) Kinship and aggression: do house sparrows spare their relatives? Behavioral Ecology and Sociobiology, 63, 1189-1196.

Tsutsui ND, Suarez AV, Holway DA, Case TJ (2000) Reduced genetic variation and the success of an invasive species. Proceedings of the National Academy of Sciences, 97, 5948-5953.

Tsutsui ND, Suarez AV, Grosberg RK (2003) Genetic diversity, asymmetrical aggression, and recognition in a widespread invasive species. Proceedings of the National Academy of Sciences, 100, 1078-1083.

Utne-Palm AC, Hart PJB (2000) The effects of familiarity on competitive interactions between threespined sticklebacks. Oikos, 91, 225-232.

Vilhunen S, Tiira K, Laurila A, Hirvonen H (2008) The bold and the variable: fish with high heterozygosity act recklessly in the vicinity of predators. Ethology, 114, 7-15.

Vrontou E, Nilsen SP, Demir E, Kravitz EA, Dickson BJ (2006) Fruitless regulates aggression and dominance in Drosophila. Nature Neuroscience, 9, 1469-1471.

Ward AJW, Hoare DJ, Couzin ID, Broom M, Krause J (2002) The effects of parasitism and body length on positioning within wild fish shoals. Journal of Animal Ecology, 71, 10-14.

Ward AJW, Duff A, Krause J, Barber I (2005) Shoaling behaviour of sticklebacks infected with the microsporidian parasite, Glugea anomala. Environmental Biology of Fishes, 72, 155-160.

Ward AJW, Webster MM, Hart PJB (2007) Social recognition in wild fish populations. Proceedings of the Royal Society B: Biological Sciences, 274, 1071-1077.

Widdig A, Streich W, Nürnberg P, Croucher PJP, Bercovitch FB, Krawczak M et al. (2006) Paternal kin bias in the agonistic interventions of adult female rhesus macaques (Macaca mulatta). Behavioral Ecology and Sociobiology, 61, 205-214.

Zeh JA, Zeh DW (1997) Homozygosity, self-recognition, and aggressive ability in the sea anemone, Anthopleura elegantissima. The American Naturalist, 149, 785-789.

Zwarts L, Magwire MM, Carbone MA et al. (2011) Complex genetic architecture of Drosophila aggressive behavior. Proceedings of the National Academy of Sciences, 108, 1707017075.

S.C. conceived the work, S.C., A.E. carried out the experiments, A.E., C.G.L. analysed the data, S.C., A.E., C.G.L. wrote the manuscript.

\section{Data accessibility}

Raw data is accessible though Dryad (doi:10.5061/ dryad.q00f8). 


\section{Supporting information}

Additional supporting information may be found in the online version of this article.

Table S1 Parameter estimates of linear mixed modelling of aggression scores (square root transformed) of individual fish nested within dyads as a function of heterozygosity.
Fig. S1 Variation in aggression levels (square root of first PCA component) of fish within dyads (dyads denoted by capital letters).

Fig. S2 Variation in heterozygosity at 32 microsatellite loci of fish within dyads (dyads denoted by capital letters). 